DOI: $\underline{10.20472 / T E .2018 .6 .2 .003 ~}$

\title{
PERFORMANCE INDICATORS, MOTIVATIONS AND BARRIERS IN ONLINE DISTANCE COURSES: A CASE STUDY AT ARAB OPEN UNIVERSITY
}

\author{
MANAL ALGHAMDI, SALEM ALANIZAN
}

\begin{abstract}
:
The number of online distance courses is growing rapidly, however online student retention has been suggested as one of the greatest weaknesses in online education (Carr, 2000; O'Brien and Renner, 2002). Retention rate is very essential to the quality of education and institutional success. This paper surveys and evaluates the barriers and motivations to online courses to understand the causes hampering effective online distance learning at Arab Open University (AOU). Moreover the paper examines student performance indicators in online distance courses. A survey was conducted to analyze motivation and barriers of online courses. While secondary data was extracted from students' information system (SIS) at AOU to evaluate students' performance indicators. Results showed the rate of students not completing online courses at AOU is $26.2 \%, 65 \%$ of them are below 30 years old. This is an indication that age and experience appear to enhance performance in online courses. Results also revealed that online courses enables more concentration which was one of the main factors encouraging AOU students to enroll and complete online courses. Convenience was also found to be a primary motivations for AOU online students' in this study. On the other hand, problems in submitting tutor marking assessment (TMA), lack of collaboration and communication with peers and a confusing course layout were identified as being the most challenging factors in AOU online courses. This study recommends for online barriers to be highly considered as they are the main cause for failing to retain more than $25 \%$ of registered students in online courses at AOU.
\end{abstract}

\section{Keywords:}

student satisfaction, online distance learning, academic performance, virtual classroom, Synchronous communication

JEL Classification: $121,123,129$

\section{Authors:}

MANAL ALGHAMDI, Arab Open University, Saudi Arabia, Email: mghamdi@arabou.edu.sa SALEM ALANIZAN, Arab Open University , Saudi Arabia, Email: salanizan@arabou.edu.sa

\section{Citation:}

MANAL ALGHAMDI, SALEM ALANIZAN (2018). Performance Indicators, motivations and barriers in online distance courses: a case study at Arab Open University. International Journal of Teaching and Education, Vol. VI(2), pp. 46-60., 10.20472/TE.2018.6.2.003 


\section{Introduction}

Studies link retention rate and student satisfaction to effective online learning. A major barrier to the growth of online courses is a low retention rate across all types of institutions (Allen \& Seaman, 2013). Program quality can be determined, in part, by calculating student completion rate (Gabrielle, 2001).

By gaining insights into the reasons why student dropout of online programs, institutions can begin to develop strategies to decrease attrition and maintain enrollment rates in their programs (Willging \& Johnson, 2004). The study by Hawksley and Owen (2002) suggested a correlation between good qualities planning, resourcing and supporting of distance learning programs and the successful outcomes that the learners and the organization itself achieve.

On another hand, the Online Learning Consortium stated that student satisfaction is one measure of success and quality for online education (Lorenzo \& Moore, 2002). However, identifying the defining elements for satisfaction has become much more dynamic and complex (Dziuban et al., 2015). According to Dziuban et al. only small number of studies conducted by investigators seeking to identify the dimensionality of student satisfaction with online learning has emerged in the past few years. The main objective of this study is to identify motivations and barriers in online courses offered by Arab Open University - Saudi Arabia Branch (AOU-SAB). Moreover, the study examines student performance indicators in online distance learning courses. The study will aim to answer the following:

What is students' performance average in online courses? What barriers do students encounter when taking online courses? What motivated students to register for online courses?

This study contributes to our understanding of the question of how to improve online learning methods to attract and retain more students. The study also offers practical contribution in the detailed analysis of what exactly motivates and hampers students in online courses.

\section{Distance learning:}

Wolfe (1996) defines distance learning as a structured or programmed learning process operating without the physical presence of an instructor. The term then evolved to describe other forms of learning, e.g. online learning, e-Learning, technology, mediated learning, online collaborative learning, virtual learning, web-based learning, etc. (Conrad, 2006).

\section{Online course:}

A subset of e-learning when course instruction and interaction between instructor and students is primarily online (Encyclopedia of E-Leadership, 2012). Interaction in AOU online course occurs synchronously which requires videoconferencing or virtual sessions.

\section{Synchronous communication:}

Means the communication is taking place in real time, as would be found in a traditional, face-to-face classroom (Abramenka, 2015). 


\section{Virtual Classroom:}

A virtual classroom is a teaching and learning environment where participants can interact, communicate, view and discuss presentations, and engage with learning resources while working in groups, all in an online setting. The medium is often through a video conferencing application that allows multiple users to be connected at the same time through the Internet, which allows users from virtually anywhere to participate (www.techopedia.com, 2017).

\section{Academic Performance:}

According to the Cambridge University Report (2003) academic performance is frequently defined in terms of examination performance. In Arab Open University (AOU), performance is considered the outcome of the midterm assessment (MTA), total tutor marked assignment (TMA) \& Final grade. This is measured by the total grade.

\section{Literature Review:}

Gagne and Shepherd (2001) found that the performance of students in online distance course didn't defer from the performance of students in the face to face course.

According to the literature, effective online distance learning is a complex practice with numerous factors and measures of success. In spite of the growth in online learning, high dropout rates have been of concern to many organizations and higher education institutions (Park \& Choi, 2009). The ability of students to complete an online course is determined by many factors. Ojokheta (2011) finds feedback pattern to have a direct effect on student ability to successfully complete an online course. Ivankova and Stick (2007) hypothesize that persistent students are generally highly motivated to complete their program of study while students who are less motivated will likely withdraw.

Lim et al. (2006) suggested that motivating online learners, and keeping student satisfaction at healthy and productive levels, can be accomplished by providing timely and frequent feedback to students; facilitating alternative communication experiences through such mechanisms as live chat and audio/video conferencing; and rewarding students with devices other than grades, such as by sharing accomplishments among peers. Additionally, the authors of this study called for instructional designers and instructors to pay closer attention to utilizing motivational strategies that result in a more outcome-oriented online instruction. Studies assessing social connectedness find persistent students believe social relationships can be established in the online environment (Hart, 2012).

Based on the findings of Aragon and Johnson (2008) study on factors influencing students' dropout from online courses, the researchers recommend having distance education policies that provide for the use of technology to deliver and/or enhance instruction and student services. The policies must address: quality control measures and course development. According to Lorenzo (2012) providing a host of student services in an online modality is a trend that is growing in usage at institutions. Administrators of this service say that it has increased communication on all levels and has helped to increase a sense of community among students, faculty, and staff (Dahl 2005). In a distance learning environment the student's ability and disposition to selfmonitor and accurately evaluate content comprehension and request help accordingly 
may represent a crucial variable, which affects both learning and teaching processes (Offir et al., 2003).

Moreover, the relationship between the student and the instructor, in terms of the students' satisfaction with their communication with the teacher, is one of the factors that distinguish students who choose to continue or dropout (Willging \& Johnson, 2004). Hartman, Dziuban, and Moskal (2000) reported very high correlations and relationships between interaction in online courses and student satisfaction.

Gagne and Shepherd (2001) state that it is a common belief that interacting with the instructor and/or with other students is somewhat hampered in a distance course. Johnston et al. (2005) noted contributors to student satisfaction as positive and effective contact and interaction with the instructor, clarity and relevance of assignments and communication, access to campus-based resources, availability of technical support, and orientation to the course and its use of technology. Additionally, "the ability of students to interact with each other reduces the feelings of isolation and improves satisfaction".

Students in the online course indicated in the course evaluation that they were less satisfied with instructor availability than face-to-face course students. However, students appreciated flexibility of online course, not having to drive to classes (Dunbar, 2004). Sun et al. (2007) identified the following seven critical factors that influence online learners' satisfaction: computer anxiety, instructor attitude, course flexibility, course quality, perceived usefulness, perceived ease of use, and diversity of assessment.

Concluding with Lorenzo (2012), an effective path to take for building any successful online learning course or program-one in which students are satisfied and do not drop out-requires, at the very least, a focus on the individual student to a position in which his or her educational needs, skills, access, and personal circumstances are identified. Then, based on this thorough identification, the appropriate levels of advisement, content, and interaction must be consistently applied to the student's course of study throughout his/her online education experience.

\section{Research Methodology}

Primary data was collected during Fall 2016/17 final exams and secondary data was extracted from data base for that semester as well. Data was analyzed by using Statistical Package for the Social Sciences software (SPSS) and Pearson correlation.

A Survey was used to analyze motivation and barriers of online courses (Appendix 1). The survey was distributed to all participants by hand during the final exams to assure high response rate. The survey consists of two sections. The first section seeks demographic information (age, gender...etc.) including questions about work experience. The second section was based on a survey designed by Vladimir Abramenka's for his Masters Dissertation on students' motivations and barriers to online education, published in 2015.

The secondary data includes course marks of the mid-term assessment (MTA), tutor marked assignment (TMA) \& final exam, along with the course grades $\left(A, B+, B, C_{+}, C\right.$, $\mathrm{D}, \mathrm{F}, \mathrm{FC}, \mathrm{FF}, \mathrm{FI}$ and Withdrawal). Data was extracted from students' information system (SIS) at Arab Open University. 
The sample of this study consisted of 168 students from Arab Open UniversityDammam center. Sample students registered to the below online courses during fall 2016/17 academic semester:
- T205B Virtual /Home
○ T215A Virtual /Campus
- T215B Virtual /Campus
- B301B Virtual/ Home
- T306B Virtual/ Home
- M359 Virtual/ Campus
○ TT284 Virtual /Home
- BE322 Virtual/Home
- M275 Virtual/Campus
- M253 Virtual/Campus
- M363 Virtual/Campus

All sampled students were included in the secondary data, however students registered to more than one online course in the same academic semester were surveyed only once, total number of surveyed students is 114 .

Statistical analysis was necessary to achieve the objectives of the study. Data analyzed using the Statistical Package for Social Sciences (SPSS) and using the following statistics:

- Pearson Correlation.

- Means.

- Standard deviation.

- Regression.

\section{Scoring Scale for Questionnaire:}

The 5-level Likert scale is used in this study. The different frequencies were given different scores ranged from 1 to 5 . (Strongly Agree) was given 5 scores, (Agree) 4 scores, (Neutral) 3 scores, (Disagree) 2 scores and (Strongly Disagree) was given 1 score. Therefore the means of the responses of the sample were distributed between 1-5 as follows:

- Low degree 1-2.33

- Medium degree 2.34-3.66

- High degree 3.67-5.00 


\section{Data analysis and findings:}

\subsection{Description of participants}

This section presents detailed description of participants which provides demographic information: age, gender ... etc. In addition to information on work status. Results in table (1) show participants gender with (73.7\%) female students and $(26.3 \%)$ male students. The results also indicated that $(58.8 \%)$ are Saudis students while $(29.8 \%)$ are Arabs and $(11.4 \%)$ of participants are native speakers. The majority of the participants are between the age of 17 to 35 with $(87.7 \%)$ and $(20.3 \%)$ are older than 36 years. Furthermore, $(51.8 \%)$ of participants have full/part time jobs and (48.2\%) unemployed. Near two third of the students were single with (60.5\%).

Table (1): Description of participants according to demographic and work status information

\begin{tabular}{|c|c|c|}
\hline Characteristic & Frequency & Percentage \\
\hline \multicolumn{3}{|r|}{ Gender } \\
\hline Male & 30 & 26.3 \\
\hline Female & 84 & 73.7 \\
\hline Total & 114 & 100 \\
\hline & & Age \\
\hline $17-25$ & 57 & 50.0 \\
\hline $26-35$ & 43 & 37.7 \\
\hline $36-45$ & 13 & 11.4 \\
\hline $46-55$ & 1 & 0.9 \\
\hline Total & 114 & 100 \\
\hline \multicolumn{3}{|r|}{ Nationality } \\
\hline Saudi & 67 & 58.8 \\
\hline Arab & 34 & 29.8 \\
\hline Other & 13 & 11.4 \\
\hline Total & 114 & 100 \\
\hline \multicolumn{3}{|r|}{ Marital Status } \\
\hline Married & 30 & 26.3 \\
\hline Married with kids & 15 & 13.2 \\
\hline Single & 69 & 60.5 \\
\hline Total & 114 & 100 \\
\hline \multicolumn{3}{|r|}{ Work status } \\
\hline Full time & 46 & 40.4 \\
\hline Part time & 13 & 11.4 \\
\hline None & 55 & 48.2 \\
\hline Total & 114 & 100 \\
\hline
\end{tabular}

\subsection{Performance indicators:}

Performance indicators involve variable that are associated with course performance measures (i.e. MTA, TMA \& final exam grade). Each course included the same assessment procedure starting with a mid-term assessment MTA then a tutor marked assignment TMA, ending with a final exam. Table (2) shows student letter grades with 168 students (number of total students registered in online courses without excluding 
those who registered more than one course on the same academic semester). Results show $(73.8 \%)$ registered students passed their courses while $(26.2 \%)$ failed to complete their online courses.

Table (2): Student letter grades extracted from AOU (N=1
\begin{tabular}{|l|l|l|}
\hline Letter grades & $\begin{array}{l}\text { Number of } \\
\text { Students }\end{array}$ & Percentage \\
\hline A & 6 & $3.57 \%$ \\
\hline B+ & 6 & $3.57 \%$ \\
\hline B & 15 & $8.93 \%$ \\
\hline C+ & 28 & $16.6 \%$ \\
\hline C & 36 & $21.43 \%$ \\
\hline D & 33 & $19.64 \%$ \\
\hline F & 8 & $4.8 \%$ \\
\hline FC & 2 & $1.2 \%$ \\
\hline FF & 15 & $8.93 \%$ \\
\hline FI & 4 & $2.4 \%$ \\
\hline W & 15 & $8.93 \%$ \\
\hline Total & 168 & $100 \%$ \\
\hline
\end{tabular}

Whereas $(F)$ is for failed total, $(F C)$ failed course assessment $C A$, (FF) failed final, $(F I)$ incomplete, and (W) for withdrawal. All considered as failing to complete their registered online courses.

The zero-order correlation were employed to observe the relationship between all variables. Result in table (3) shows a strong relationship between all variables with value .50 to 1.0 (Cohen, 1988). TMA grade $(.78, p<.01)$, MTA grade $(.79, p<.01)$ and final grade $(.94, p<.01)$ are significantly correlated with total grade. Accordingly, TMA grade $(.62, p<.01)$, MTA grade $(.61, p<.01)$ are significantly correlated with final grade. Thus, both TMA and MTA are strongly related to overall performance.

TMA grade $(.50, p<.01)$ is significantly correlated to MTA grade. The lowest significant correlation is $\operatorname{MTA}(.50, p<.01)$ and the highest significant is final grade $(.94, p<.01)$. 
Table (3): Correlation matrix extracted from AOU ( $N=168)$

\begin{tabular}{|c|c|c|c|c|c|c|}
\hline $\begin{array}{l}\text { Assessme } \\
\mathrm{nt}\end{array}$ & Mean & SD & TMA & MTA & Final & Total \\
\hline $\begin{array}{l}\text { TMA } \\
\text { grade }\end{array}$ & 14.42 & 5.44 & 1 & & & \\
\hline $\begin{array}{l}\text { MTA } \\
\text { grade }\end{array}$ & 14.80 & 6.41 & $.50^{\star \star}$ & 1 & & \\
\hline $\begin{array}{l}\text { Final } \\
\text { grade }\end{array}$ & 25.67 & 12.67 & $.62^{\star \star}$ & $.61^{\star *}$ & 1 & \\
\hline $\begin{array}{l}\text { Total } \\
\text { grade }\end{array}$ & 54.89 & 21.20 & $.78^{\star *}$ & $.79^{\star \star}$ & $.94^{\star *}$ & 1 \\
\hline
\end{tabular}

${ }^{*} \mathrm{p}<.05,{ }^{* *} \mathrm{p}<.01$

Gender was related to performance with female students performing better than males in online courses. Table (4) shows that the majority of (A) students are females.

Table (4): Female/Male Students' Percentages of letter grades

\begin{tabular}{|c|c|c|c|c|c|c|c|c|c|}
\hline & $\begin{array}{c}\text { \% of } \\
\text { A }\end{array}$ & $\begin{array}{c}\text { \% of } \\
\text { B }\end{array}$ & $\begin{array}{c}\text { \% of } \\
\text { B+ }\end{array}$ & $\begin{array}{c}\% \text { of } \\
\text { C }\end{array}$ & $\begin{array}{c}\% \text { of } \\
\text { C+ }\end{array}$ & $\begin{array}{c}\% \text { of } \\
\text { D }\end{array}$ & $\begin{array}{c}\% \text { of } \\
\text { Faile } \\
\text { d }\end{array}$ & $\begin{array}{c}\% \text { of } \\
\text { FI }\end{array}$ & $\begin{array}{c}\% \text { of } \\
\text { W }\end{array}$ \\
\hline $\begin{array}{c}\text { Male } \\
\text { student } \\
\text { s }\end{array}$ & 0.595 & 2.97 & 1.19 & 5.357 & 4.76 & 4.167 & 2.976 & 0.595 & 5.57 \\
\hline $\begin{array}{c}\text { Female } \\
\text { student } \\
\text { s }\end{array}$ & 2.96 & 5.95 & 2.381 & 16.07 & 11.9 & 15.476 & 11.9 & 1.7857 & 5.357 \\
\hline
\end{tabular}

Results as shown in table (5) also suggest that most of students whom did not complete the registered online course are from the age category below 30 years with $65.9 \%$ percent from all failing students.

Table (5): Letter grades according to students' age categories

\begin{tabular}{|c|c|c|c|c|c|c|c|c|c|c|c|}
\hline $\begin{array}{c}\text { Age } \\
\text { Categories as } \\
\text { shown on SIS }\end{array}$ & A & B & B+ & C & C+ & D & F & FC & FF & FI & W \\
\hline $\mathbf{2 1 - 2 4}$ & 1 & 6 & 3 & 12 & 14 & 7 & 1 & 0 & 1 & 0 & 4 \\
\hline $\mathbf{2 5 - 2 9}$ & 1 & 8 & 2 & 13 & 10 & 21 & 4 & 0 & 12 & 2 & 5 \\
\hline $30-39$ & 3 & 1 & 1 & 7 & 2 & 4 & 3 & 2 & 2 & 2 & 6 \\
\hline $40-49$ & 1 & 0 & 0 & 4 & 2 & 1 & 0 & 0 & 0 & 0 & 0 \\
\hline
\end{tabular}




\section{.3 Motivations of online courses}

This practice contained (8) statements that investigate motivations of online courses.

Means and standard deviation for the responses of the sample on the question about online courses motivations in AOU are calculated. It is interested to find that students find it easier to concentrate in online courses with a mean of (2.64) and SD (1.3). The second popular statement is "Prepare me better for the future." $(M=2.61 \mathrm{SD}=1.23)$. This was followed by "I work better at my own place." (M=2.47 SD=124). Results in table (6) show that students consider online courses as an opportunity for professional networking and convenient as two of the top five statements with a mean of $(2.46,2.38)$ and SD $(1.099,1.140)$.

The last three popular statements were "Online classes fit my schedule better." (M=2.32 $S D=1.27)$, "I enjoy learning how to use new technologies." $(M=2.32 S D=1.173)$ and "No transportation to class required." (M=2.19 SD=1.088).

Table (6) Means \& SD for responses about online courses motivations

\begin{tabular}{|r|l|l|l|l|}
\hline Rank & Statement & Mean & SD & $\begin{array}{l}\text { Category of } \\
\text { importance }\end{array}$ \\
\hline 1 & Easier to concentrate. & 2.64 & $\begin{array}{l}1.31 \\
1\end{array}$ & Medium \\
\hline 2 & Prepare me better for the future. & 2.61 & $\begin{array}{l}1.23 \\
8\end{array}$ & Medium \\
\hline 3 & I work better at my own place. & 2.47 & $\begin{array}{l}1.24 \\
2\end{array}$ & Medium \\
\hline 4 & Professional networking opportunities. & 2.46 & $\begin{array}{l}1.09 \\
9\end{array}$ & Medium \\
\hline 5 & Convenience. & 2.38 & $\begin{array}{l}1.14 \\
0\end{array}$ & Medium \\
\hline 6 & Online classes fit my schedule better. & 2.32 & $\begin{array}{l}1.27 \\
3\end{array}$ & Medium \\
\hline 7 & $\begin{array}{l}\text { I enjoy learning how to use new } \\
\text { technologies. }\end{array}$ & 2.29 & $\begin{array}{l}1.17 \\
3\end{array}$ & Medium \\
\hline 8 & No transportation to class required. & 2.19 & $\begin{array}{l}1.08 \\
8\end{array}$ & Medium \\
\hline
\end{tabular}

\subsection{Online courses challenges}

Results as shown in table (7) revealed the participants responses about online courses challenges. The first three popular statements were: "Difficulty submitting assignments", "Collaborating with peers" and "Confusing layout/organization" (Means= $3.22,2.75,2.74)$ and $(S D=1.2,1.09,1.073)$ respectively. The fourth challenge was "lack of direction" $(\mathrm{M}=2.71 \mathrm{SD}=1.028)$. While "feeling isolated." came on the fifth place with 
$(\mathrm{M}=2.70 \mathrm{SD}=1.189)$. The least popular challenges were "Using new technology", "Managing time/procrastination", "Lack of social interaction" (M= 2.46, 2.46, 2.43) and $(\mathrm{SD}=1.146,1.098,1.081)$.

Table (7): Means \& SD for responses about online courses challenges

\begin{tabular}{|r|l|l|l|l|}
\hline Rank & \multicolumn{1}{|c|}{ Statement } & Mean & SD & $\begin{array}{l}\text { Category of } \\
\text { importance }\end{array}$ \\
\hline 1 & Difficulty submitting assignments. & 3.22 & 1.203 & Medium \\
\hline 2 & Collaborating with peers. & 2.75 & 1.096 & Medium \\
\hline 3 & Confusing layout/organization. & 2.74 & 1.073 & Medium \\
\hline 4 & Lack of direction. & 2.71 & 1.028 & Medium \\
\hline 5 & Communicating with instructor. & 2.70 & 1.189 & Medium \\
\hline 6 & Feeling isolated. & 2.67 & 1.217 & Medium \\
\hline 7 & Lack of timely feedback. & 2.61 & 1.085 & Medium \\
\hline 8 & Using new technology. & 2.46 & 1.146 & Medium \\
\hline 9 & Managing time/procrastination. & 2.46 & 1.098 & Medium \\
\hline 10 & Lack of social interaction. & 2.43 & 1.081 & Medium \\
\hline
\end{tabular}

\section{Conclusions:}

Even though the results of this study cannot be generalized, results from this research are promising and concluded bellow.

\section{1: Students' performance average in online courses:}

1. The strongest predictors of online course performance which is measured by the total grade are TMA grade $(.62, \mathrm{p}<.01)$ and final grade $(.94, \mathrm{p}<.01)$.

2. Students letter grade average in online courses is $(C)$, with $21.43 \%$ of students.

3. An interesting finding in the research shows that the rate of students not completing online courses ( $\mathrm{F}, \mathrm{FC}, \mathrm{FF}, \mathrm{FI}$ and $\mathrm{W}$ ) is $26.2 \%$ which is mostly related to the barriers of online courses students mentioned in the distributed research survey.

4. The research shows that female students perform better than male students in online courses, a finding that has been reported elsewhere (Brown \& Liedholm, 2002 and Alstete \& Beutell, 2004).

5. More than $65 \%$ of students failing to complete their registered online courses (29 students out of 44) are below 30 years old. This indicates that age and experience appear to enhance performance in online courses (Alstete \& Beutell, 2004) as older students are more committed to completing online courses successfully. 


\section{2: Motivation to online courses:}

1. The study sample responses indicate that online courses enables more concentration which encourages students to enroll and complete online courses. According to Hidi and Renninger (2006), concentration is an affective component of positive emotion and a cognitive component that enhances interest which is central to motivation.

2. Majority responses show that online students believe that online education prepares them better for the future as sophisticated technologies are employed to enhance communications and interactions among students and between instructors and students in online learning environments (Liaw, 2002).

3. Convenience was a primary motivations for online students'. This finding closely mirror the Noel-Levitz (2010) survey results, which indicated that the three primary motivations for students choosing online programs were convenience, flexibility, and the ability to fit courses into a current work schedule. (Harris \& Martin, 2012)

\section{3: Barriers to online learning:}

1. The majority of students identify submitting TMA as being the most challenging in online courses.

2. The summary of students' concerns indicates that the majority also identify collaboration and communication with peers as areas that are very challenging in online courses. This finding is supported by literature that also indicates that most students express collaboration as a major barrier to taking an online class (Abramenka, 2015).

3. A confusing layout of the course was on top of the challenges although a course syllabus -calendar is shared on the learning management system LMS in online courses although a course calendar. Course design was also founded to be a main reason to not completing online course by Aragon and Johnson (2008).

4. Students' least concern was the social technical factor. Logging in and following up online classes was not a great challenge for students.

\section{Recommendations:}

Throughout the study it was noticed that some factor motivate AOU students to join an online course more than others while some factor are considered challenging during an online course and may hamper the completion of the course. Therefore recommendations are directed to both AOU academic affairs and scholars in the academic field as following:

1. Online barriers must be highly considered as they are the main cause to $26 \%$ of students not completing online courses in AOU.

2. Instructor must find a clear way to communicate the course layout to students not only depending on posting the course calendar on learning management system (LMS).

3. Mechanism of communication and direction between online students and instructor should be very clear from the beginning. 
4. Difficulties in submitting the total tutor marked assignment (TMA) related to cut-off date and submitting process should be reviewed carefully.

5. Each face-to-face course should be available for students online as the benefits of AOU online education are high.

\section{Future research can be conducted on the following:}

1. Study factors related to students' dropout from AOU courses.

2. To find out factors contributing to students' persistence in completing online course.

3. A comparative study in students' performance between face-to-face and online courses.

4. Study on enhancing the quality of online courses.

\section{References}

Abramenka, Vladimir, "Students' Motivations and Barriers to Online Education" (2015). Masters Theses.Paper 776.

Allen, E. I., \& Seaman, J. (2013). Changing course: Ten years of tracking online education in the United States. Sloan Consortium. P.O. Box 1238, Newburyport, MA 01950.

Alstete, Jeffrey W. and Beutell, Nicholas J. (2004) "Performance indicators in online distance learning courses: a study of management education", Quality Assurance in Education, Vol. 12 Issue: 1, pp.6-14. https://doi.org/10.1108/09684880410517397

Aragon, Steven R., and Johnson, Elaine S. (2008). Factors Influencing Completion and Noncompletion of Community College Online Courses. The Amer. Journal of Distance Education, 22: 146-158, 2008. https://doi.org/10.1080/08923640802239962

Brown, B.W. and Liedholm, C. (2002), "Can Web courses replace the classroom in principles of macroeconomics?". The American Economic Review, Vol. 92 No. 2, pp. 444-8. https://doi.org/10.1257/000282802320191778

Cambridge University Reporter. (2003). Indicators of academic performance. Available: http://www.admin.cam.ac.uk/reporter/2002-03/weekly/5915/ [Accessed Feb. 17, 2017]

Conrad, D. (2006). E-Learning and Social Change: An Apparent Contradiction. In M.Beaudoin (Ed.), Perspectives on higher education in the digital age. (pp. 21-33). NewYork: Nova Science Publishers

Dahl, Judy. 2005. "Online Services Keep Syracuse Students Satisfied." Distance Education Report 1 November.

Dunbar, A. E. (2004). Genesis of an online course. Issues in Accounting Education, 19(3), $321-343$. https://doi.org/10.2308/iace.2004.19.3.321

Dziuban, C., Moskal, P., Hermsdorfer, A., DeCantis, G., Norberg, A., \& Bradford, G., (2015) A deconstruction of blended learning. Presented at the $11^{\text {th }}$ annual Sloan-C blended learning conference and workshop.

Encyclopedia of E-Leadership, Counseling and Training. Copyright: (C) 2012 
Gabrielle, D. M. Distance learning: An examination of perceived effectiveness and student satisfaction in higher education. In Proceedings of SITE 2001, Orlando, FL: AACE, 183-188, 2001.

Gagne, Margaret and Morgan Shepherd, A Comparison Between a Distance and a Traditional Graduate $\begin{array}{llll}\text { Accounting Class. } & \text { T.H.E. Journal, April } 2001 .\end{array}$ (http://www.thejournal.com/magazine/vault/A3433.cfm)

Harris, Heidi S. and Martin, Elwyn W. (2012) "Student Motivations for Choosing Online Classes," International Journal for the Scholarship of Teaching and Learning: Vol. 6: No. 2, Article 11. Available at: https://doi.org/10.20429/ijsotl.2012.060211

Hart, Carolyn (2012). Factors Associated With Student Persistence in an Online Program of Study: A Review of the Literature. Journal of Interactive Online Learning. v11 n1.

Hartman, J., Dziuban, C., \& Moskal, P. (2000). Faculty satisfaction in ALNs: A dependent or independent variable? Journal of Asynchronous Learning Networks, 4(3), 155-177. Retrieved August 28, 2008, from http://www.sloan-c.org/publications/jaln/v4n3/v4n3_hartman.asp

Hawksley, R., and Owen, J. Going the Distance: Are There Common Factors in High Performing Distance Learning? Research Report. London, England: Learning and Skills Development Agency, 2002.

Hidi, S. \& Renninger, K. A. (2006). The four-phase model of interest development. Educational Psychologist, 42(2), 111-127. https://doi.org/10.1207/s15326985ep4102_4

Ivankova, N. V., \& Stick, S. L. (2005). Collegiality and community-building as a means for sustaining student persistence in the computer-mediated asynchronous learning environment. Online Journal of Distance Learning Administration, 8(3).

Johnston, James, Jeff Killion, and Jody Oomen. 2005. "Student Satisfaction in the Virtual Classroom." The Internet Journal of Allied Heal Sciences and Practice 3 (2), April.

Kristine Holloway (2012). Fair Use, Copyright, and Academic Integrity in an Online Academic Environment. Encyclopedia of E-Leadership, Counseling and Training. https://doi.org/10.4018/978-1-61350-068-2.ch022

Liaw, S. (2002). Understanding user perception of world-wide Web environments. Journal of Computer Assisted Learning, 18(2), 137-148. https://doi.org/10.1046/j.0266-4909.2001.00221.x

Lim, Doo Hun, Michael Lane Morris, and Seung-Won Yoon. 2006. "Combined Effect of Instructional and Learner Variables On Course Outcomes Within An Online Learning Environment." Journal of Interactive Online Learning 5 (3), Winter.

Lorenzo, G. \& Moore, J. (2002). The Sloan Consortium report to the nation: Five pillars of quality online education. Needham, MA: Sloan Center. Dziuban et al., 2015

Lorenzo, George (2012) "A Research Review about Online Learning: Are Students Satisfied? Why do Some Succeed and Others Fail? What Contributes to Higher Retention Rates and Positive Learning Outcomes?" Internet Learning: Vol. 1: Iss. 1, Article 5.

Noel-Levitz national online learners priorities report. (2010). Retrieved from https://www.noellevitz.com/Our+Services/Retention/Tools/Priorities+Survey+for+Online+Learners l

O'Brien, B. \& Renner, A. (2002). Online student retention: Can it be done? Paper presented at the EDMEDIA 2002 World Conference on Educational Multimedia, Hypermedia \& Telecommunications, $\begin{array}{lllll}\text { Denver, } & \text { CO } & \text { Retrieved } & \text { October } & 2,\end{array}$ 
from: http://www.eric.ed.gov/ERICDocs/data/ericdocs2sql/content storage 01/0000019b/80/1b/1 9/90.pdf

Offir, Baruch, Ingrid Barth, Yoseph Lev and Arkady Shteinbok (2003). Teacher-student interactions and learning outcomes in a distance learning environment. The Internet and Higher Education 6 (2003) 65-7568. https://doi.org/10.1016/S1096-7516(02)00162-8

Ojokheta, K. O. (2011). A path-analytic study of some correlates predicting persistence and student's success in distance education in Nigeria. Turkish Online Journal of Distance Education, 11(1).

Park, Ji-Hye; and Choi, Hee Jun (2009). Factors Influencing Adult Learners' Decision to Drop Out or Persist in Online Learning. Educational Technology \& Society, v12 n4 p207-217 2009

Sun, Pei-Chen, Ray J. Tsai, Glenn Finger, Yueh-Yang Chen, and Dowming Yeh. 2007. "What Drives a Successful e-Learning? An Empirical Investigation of the Critical Factors Influencing Learner Satisfaction." Computers \& Education, in press.

Techopedia Dictionary Definition, Virtual Classroom. Retrieved February 20, 2017, from www.techopedia.com

Willging, P. A., \& Johnson, S. D. (2004). Factors that influence students' decision to drop out of online courses. Journal of Asynchronous Learning Network, 8(4), 105-118. Hawksley and Owen (2002)

Wolfe, T. E. (1996) Putting interaction into interactive television. In Proceedings, 17th Annual Distance Learning Conference, University of Wisconsin, Madison, WI. 